\title{
Effect of bilberry extract on slowing high-myopia progression in children: 2-year follow-up study
}

This article was published in the following Dove Press journal: Clinical Ophthalmology

\author{
Ismail Ahmed Nagib Omar \\ Ophthalmology Department, Faculty \\ of Medicine, Minia University, \\ El-Minya, Egypt
}

\begin{abstract}
Aim: To evaluate the effect of oral Difrarel on progression of high myopia in children and to study myopia course after its discontinuation.

Methods: A total of 64 highly myopic children were enrolled in this study. Patients were divided into two equal groups: group 1 was administered Difrarel for 1 year and stopped its intake for another year, and group 2 (control) did not take Difrarel. Refraction and axial length of the right eye of every subject were measured every 6 months in both groups.

Results: Each group had 32 eyes of 32 patients. The mean age was $9.34 \pm 2.27$ years in group 1 and $9.33 \pm 2.2$ years in group 2. Mean refraction and axial length at the start of the study were $-10.78 \pm 2.6 \mathrm{D}$ and $23.7 \pm 1.2 \mathrm{~mm}$, respectively, in group 1 , and $-10.5 \pm 2.55 \mathrm{D}$ and $23.9 \pm 1.4 \mathrm{~mm}$ in group 2 . Refraction and axial length measurements every 6 months revealed statistically significant lower numbers in group 1 than group 2 after 1 year. After discontinuation of the drug, the difference between both groups remained significant.

Conclusion: Oral Difrarel slowed axial elongation and stopped myopia progression in children with high myopia. The drug effect was consistent after its discontinuation for 1 year.

Keywords: high myopia in children, Difrarel, axial myopia, progressive myopia
\end{abstract}

\section{Introduction}

High myopia represents a major health problem in children. There is an increased prevalence of myopia in many countries. ${ }^{1}$ However, there are no prevalence data about myopia in Egypt, apart from individual studies. A preliminary national survey of disabilities done in Cairo, the Egyptian capital, reported that visual disabilities comprised $34 \%$ of recorded disabilities. ${ }^{2}$ Another preliminary screening study found $22.1 \%$ of school children suffered from a refractive error. ${ }^{3}$

High myopia is often associated with serious ocular complications, such as retinal detachment, macular degeneration, choroidal neovascular membrane, cataract, and glaucoma leading to permanent visual loss. ${ }^{4}$ These complications are frequently related to the degree of myopic error, as higher-myopia patients carry increased risk of developing complications. ${ }^{5}$ Research has found that spending more time outdoors and reducing the need for close work may protect against myopia development and progression. ${ }^{6}$ Other studies have reported slowing myopia progression by using drugs, such as atropine, bifocal spectacle lenses, multifocal contact lenses, orthokeratology, and even surgically by scleral reinforcement. ${ }^{7}$

However, most of these studies found limited effect on slowing myopia progression and lacked the follow-up of myopia progression after discontinuation of the studied modalities. Bilberry is rich in anthocyanins, which belong to a parent class of bioflavonoids. ${ }^{8}$ Anthocyanins are suggested to improve visual functions and are
Correspondence: Ismail Ahmed Nagib Omar

Ophthalmology Department, Faculty of Medicine, Minia University, Kornish El-Nile Street, El-Minya 6I I I I, Egypt Tel +20 I002554II6

Email ismailmoftahI@yahoo.com 
important in maintaining eye health..$^{9-11}$ The aim of this study was to investigate the effect of long-term oral Difrarel use (contains anthocyanins from bilberry extracts) on progression of high myopia in children, and to study the course of myopia after Difrarel discontinuation, which to date has not been studied.

\section{Methods}

This prospective case-control study was carried out on 64 children between February 2014 and July 2017. Children included in this study fulfilled criteria of an age range of 6-14 years, myopia $>6 \mathrm{D}$, and normal anterior and posterior segments. Children with amblyopia or any abnormal ocular motility were excluded. In addition, uncooperative patients or those who did not complete the follow-up plan were omitted from the study. Because Difrarel contains sucrose, it was not prescribed for children with fructose intolerance, glucose malabsorption, galactose malabsorption, or invertase-isomaltase deficiency.

For all subjects participating in this study, their parents or legal guardians were asked to sign written detailed consent explaining the study and follow-up plan. The study was designed respecting the expected ethical aspects. It was performed according to the Declaration of Helsinki 1964 as revised in 2008 and approved by the institutional review board and medical ethics committee of Minia University Hospital.

Right eyes of the children who participated in the study were subjected to full ophthalmologic examination: anteriorsegment examination with slit-lamp biomicroscopy (SL450; Nidek, Gamagori, Japan), posterior-segment examination using an indirect ophthalmoscope and slit lamp with highplus lenses, ocular motility assessment, cycloplegia with cyclopentolate $1 \%$ eyedrops three times every 10 minutes, then measurement of refractive error after 1 hour using an autorefractometer, and finally axial length measurement with A-scan.

Children were randomly divided into two groups. Group 1 (Difrarel) comprised 32 myopic children administered twicedaily Difrarel E $50 \mathrm{mg}$ tablets for 20 days every month for 1 year and stopping afterward. Difrarel $\mathrm{E}$ is composed of anthocyanosidic extracts of Vaccinium myrtillus (bilberry extract) and $\alpha$-tocopherol acetate (vitamin E; Leurquin Laboratories). Group 2 (control) had 32 myopic children who did not take Difrarel. The study plan was to measure cycloplegic refraction and axial length in participating children every 6 months for 2 years: for children in group 1, 1 year while they were on Difrarel and another year after stopping it.

\section{Statistical analyses}

Data collected were statistically analyzed using SPSS for Windows version 16 . Results are presented as mean \pm SD. Student's $t$-tests were done for analysis of cycloplegic refraction and axial length measurements of both groups at the start of the study (baseline) and every 6 months for 2 years. Correlation was performed using Pearson's correlation coefficient $(r) . P<0.05$ was considered the cutoff for significance.

\section{Results}

A total of 64 eyes of 64 children (34 males and 30 females) were enrolled in the study. They had a mean age of $9.34 \pm 2.21$ years $(6-13.5$ years). They all had high myopia, with mean refraction of $-10.56 \pm 2.55 \mathrm{D}(-6.5$ to $-15 \mathrm{D})$. Group 1 was children on Difrarel therapy: 18 males and 14 females. Group 2 was children who did not receive Difrarel (control): 16 males and 16 females. The mean age of the Difrarel group was $9.34 \pm 2.27$ years and that of the control group was 9.33 \pm 2.2 years, and differences in age or sex between the two groups were not significant $(P>0.05)$.

The mean baseline refraction of the Difrarel group was $-10.78 \pm 2.6 \mathrm{D}$ and that of the control group was $-10.5 \pm 2.55 \mathrm{D}$, and the difference between them was not of statistical significance $(P>0.05$; Table 1$)$. Changes in the Difrarel group refraction were studied every 6 months and compared to refraction in the control group. There was no statistically significant difference after 6 months between the two groups $(P=0.2)$, but after 12,18 , and 24 months the change in refraction of the Difrarel group was significantly less than that of the control group $(P<0.05$ in all; Table 1).

At the start of the study, the mean baseline axial length of the Difrarel group was $23.7 \pm 1.2 \mathrm{~mm}$, not statistically significantly different than that of the control group, which was $23.9 \pm 1.4 \mathrm{~mm}(P>0.05)$. Also, axial length changes showed no statistical significant differences between the two groups after 6 months $(P>0.05)$, though changes in axial length measurements started to be statistically significant at 12,18 , and 24 months (Table 2).

Table I Refraction at baseline and 6-month intervals

\begin{tabular}{l|l|l|l}
\hline & $\begin{array}{l}\text { Group I } \\
\text { (Difrarel) }\end{array}$ & $\begin{array}{l}\text { Group 2 } \\
\text { (control) }\end{array}$ & $P$-value \\
\hline Baseline & $-10.78 \pm 2.6$ & $-10.5 \pm 2.55$ & 0.7 \\
After 6 months & $-1 \mathrm{I} \pm 2.6$ & $-10.9 \pm 2.7$ & 0.2 \\
After I2 months & $-11.05 \pm 2.6$ & $-11.56 \pm 2.6$ & $0.04^{\mathrm{a}}$ \\
After I8 months & $-1 \mathrm{I} .14 \pm 2.7$ & $-11.9 \pm 2.6$ & $0.02^{\mathrm{a}}$ \\
After 24 months & $-1 \mathrm{II} 17 \pm 2.5$ & $-12.3 \pm 2.6$ & $0.0 \mathrm{I}^{\mathrm{a}}$ \\
\hline
\end{tabular}

Note: ${ }^{a} P<0.05$. 
Table 2 Axial length at baseline and 6-month intervals

\begin{tabular}{l|l|l|l}
\hline & $\begin{array}{l}\text { Group I } \\
\text { (Difrarel) }\end{array}$ & $\begin{array}{l}\text { Group 2 } \\
\text { (control) }\end{array}$ & $P$-value \\
\hline Baseline & $23.7 \pm 1.2$ & $23.9 \pm 1.4$ & 0.4 \\
After 6 months & $23.76 \pm 1.24$ & $24.27 \pm 1.4$ & 0.1 \\
After I2 months & $23.85 \pm 1.23$ & $24.5 \pm 1.4$ & $0.04^{\mathrm{a}}$ \\
After 18 months & $23.87 \pm 1.2$ & $24.67 \pm 1.5$ & $0.02^{\mathrm{a}}$ \\
After 24 months & $23.9 \pm 1.2$ & $24.8 \pm 1.5$ & $0.008^{\mathrm{a}}$ \\
\hline
\end{tabular}

Note: ${ }^{\mathrm{P}}<0.05$.

Differences between studied values of refraction and axial length at the start of the study were compared with those at 6 and 12 months. Refraction and axial length of the Difrarel group after 6 months were stabilized by $33 \%$ and $43 \%$ of values in the control group, respectively, and were $69 \%$ and $74 \%$, respectively, after 12 months (Table 3 ).

Results at 12 months were compared with those at 18 and 24 months to show differences after drug stoppage. Differences between 12 and 18 months in group 1 revealed refraction stabilization of $69 \%$ in controls: $75 \%$ in axial length became $67 \%$ and $74 \%$, respectively, after 24 months (Table 3). Pearson's correlation coefficient was used to study the association between axial length and refraction in each group separately, revealing significant negative correlations at all intervals of follow-up $(P<0.05)$.

\section{Discussion}

Management of high myopia in children represents a challenge, due to heavy spectacles, intolerance to contact lenses, and inconvenience of refractive surgery because of unstable refraction. Many researchers have studied various methods to delay myopia progression to guard against serious complications. In this study, high-myopia children were evaluated for myopia progression while taking Difrarel (a bilberry extract) for 1 year and further assessed for another year after stopping it. These patients were compared with another highly myopic group who did not take the drug.

In a retrospective study done by Vasudevan et al, they reported that undercorrection of myopia did not slow myopia: instead, it lead to its progression, and degree of undercorrection was related to the degree of progression. ${ }^{12}$ Optimal correction of the myopic error was the target in all patients of the current study. There were no statistically significant differences between the groups concerning age, sex, baseline spherical errors, or baseline axial length measurements to avoid bias and to cancel any other factor that may have affected the data measured.

During evaluation of refractive changes every 6 months, it was noticed that the amount of myopic shift in refraction in the Difrarel group was less than that of the control group. The difference between the groups was not statistically significant after the first 6 months, but after 12 months the difference became significant, which means that the gap in refraction widened by time. Furthermore, after drug intake had been stopped, there was still a significant difference in refraction after 18 and 24 months. This showed that the drug effect was consistent during the second year of follow-up.

On the other hand, studying the effect of the drug on the axial length measurements revealed that the Difrarel group showed lower values than the control group, and this difference was statistically insignificant between the two groups after 6 months. However, axial length measurements started to differ significantly after 12,18 , and 24 months follow-up. As such, the drug affected axial length significantly after 1 year and its effect lasted for another year.

With regard to differences in refraction and axial length measurements at the start of the study with those at 6 and

Table 3 Differences in refraction and axial length at different follow-up intervals

\begin{tabular}{l|l|l|l|l}
\hline Variables & Group I (Difrarel) & Group 2 (control) & Difference & P-value \\
\hline Difference between baseline and 6 months & & & & \\
$\quad$ Refraction & $0.01 \pm 0.05$ & $0.15 \pm 0.1$ & $33 \%$ & $0.00 \mathrm{I}^{\mathrm{a}}$ \\
$\quad$ Axial length & $0.22 \pm 0.2$ & $0.39 \pm 0.2$ & $43 \%$ & $0.004^{\mathrm{a}}$ \\
Difference between baseline and I2 months & $0.12 \pm 0.08$ & $0.39 \pm 0.16$ & $69 \%$ & $0.00 \mathrm{I}^{\mathrm{a}}$ \\
$\quad$ Refraction & $0.26 \pm 0.17$ & $1.03 \pm 0.3$ & $74 \%$ & $0.00 \mathrm{I}^{\mathrm{a}}$ \\
$\quad$ Axial length & $0.05 \pm 0.06$ & $0.16 \pm 0.07$ & $69 \%$ & $0.00 \mathrm{I}^{\mathrm{a}}$ \\
Difference between I2 and I8 months & $0.1 \pm 0.12$ & $0.4 \pm 0.12$ & $75 \%$ & $0.0 \mathrm{I}^{\mathrm{a}}$ \\
$\quad$ Refraction & & & & \\
$\quad$ Axial length & $0.1 \pm 0.06$ & $0.3 \pm 0.1$ & $67 \%$ & $0.03^{\mathrm{a}}$ \\
Difference between I2 and 24 months & $0.2 \pm 0.1$ & $0.76 \pm 0.19$ & $74 \%$ & $0.00 \mathrm{I}^{\mathrm{a}}$ \\
$\quad$ Refraction & & & \\
Axial length & & & \\
\hline
\end{tabular}

Note: ${ }^{\mathrm{P}}<0.05$. 
12 months, there was significantly less difference in the Difrarel group. Percentages of difference at 12 months were nearly double those at 6 months. These percentages remained nearly the same for 1 year after discontinuation of Difrarel intake. Axial length and refraction had significant negative correlations at all follow-up intervals, which confirmed the relation between increased axial length and increased myopia.

The main limitation in this study was the small sample, which was due to frequent dropouts during the study period. Frequent dropouts have been encountered in other studies. ${ }^{13-15}$ However, larger-sample studies with longer follow-up should be done to confirm these results. Studying the drug effect on lower grades of myopia was not studied, which is another limitation.

Kamiya et al studied the effect of fermented bilberry extracts on visual outcomes in myopic eyes. ${ }^{16}$ They concluded an increase in subjective accommodation and mesopic contrast sensitivity, but they did not study the drug's effect on refraction or axial length. A previous study assessed the effect of oral Difrarel on myopic children with a 6-month follow-up. They found myopia progression was controlled in those with mild and high myopia, with no effect on moderate myopia. This may be attributed to the short period of drug administration, in addition to the fact they did not study myopia progression after stopping the drug. ${ }^{17}$ A study done on guinea pigs demonstrated that orally administered Difrarel inhibited axial elongation in form-deprivation myopia, and hence might be useful for preventing myopia progression in clinical practice. ${ }^{18}$ This agrees with the current study results, as Difrarel slowed axial elongation significantly.

A study conducted in Singapore studied the effect of different concentrations of atropine on myopia progression. They called their study ATOM (Atropine in the Treatment of Myopia). Although they were satisfied with myopia-progression control, they were faced by many atropine side effects, such as hypersensitivity reactions in skin and conjunctiva, impaired near work in some children caused by pupil dilation, and rebound progression in myopia after atropine treatment was stopped. ${ }^{19-21}$ In the present study, the myopia stabilization achieved was stable for 1 year after Difrarel stoppage, added to excellent tolerance of the drug, with no documented side effects during the study period. Many researchers have studied the effect of different contact-lens styles on myopia progression. The best style in controlling myopia progression was multifocal contact lenses. However, complications of contact-lens use, especially microbial keratitis, have been documented among several studies. ${ }^{22-25}$
Orthokeratology has proven an effective method in controlling myopia and slowing its progression by many authors. ${ }^{26,27}$ Nevertheless, it has been reported to have many complications, such as microbial keratitis, conjunctivitis, and peripheral ulcer. ${ }^{28,29}$ In 2016, Wu et al reported that the effects of orthokeratology on axial length growth and refraction retention were $30 \%$ and $67 \%$, respectively, compared to spectacle wearers. In the current study, Difrarel caused axial length and refraction-retention effects of $69 \%$ and $74 \%$, respectively, after 1 year's therapy, and this effect remained consistent throughout the second year (67\% and $74 \%)$.

\section{Conclusion}

Oral Difrarel for 1 year was associated with slowing of axial elongation and control of myopia progression in children with high myopia. Its effect was consistent even after discontinuation of the drug for 1 year. Tolerance of the drug was excellent, with no documented side effects during the study period, which gives Difrarel a promising role in pediatric myopia control.

\section{Data availability}

Unpublished data are available upon request from the author.

\section{Acknowledgment}

The author did not receive any external funding.

\section{Disclosure}

The author reports no conflicts of interest in this work.

\section{References}

1. Williams KM, Bertelsen G, Cumberland P, et al; European Eye Epidemiology (E(3)) Consortium. Increasing prevalence of myopia in Europe and the impact of education. Ophthalmology. 2015;122(7):1489-1497.

2. Shukrallah A. The current state of the disability question in Egypt: preliminary national study. Cairo, Association for Health and Environmental Development. 1997.

3. El-Bayoumy BM, Saad A, Choudhury AH. Prevalence of refractive error and low vision among schoolchildren in Cairo. East Mediterr Health J. 2007;13(3):575-579.

4. Holden B, Sankaridurg P, Smith E, Aller T, Jong M, He M. Myopia, an underrated global challenge to vision: where the current data takes us on myopia control. Eye (Lond). 2014;28(2):142-146.

5. Flitcroft DI. The complex interactions of retinal, optical and environmental factors in myopia aetiology. Prog Retin Eye Res. 2012;31(6): $622-660$.

6. He M, Xiang F, Zeng Y, et al. Effect of time spent outdoors at school on the development of myopia among children in China: a randomized clinical trial. JAMA. 2015;314(11):1142-1148.

7. Chassine T, Villain M, Hamel CP, Daien V. How can we prevent myopia progression? Eur J Ophthalmol. 2015;25(4):280-285.

8. Tsuda T. Dietary anthocyanin-rich plants: biochemical basis and recent progress in health benefits studies. Mol Nutr Food Res. 2012; 56(1):159-170 
9. Middleton E jr, Kandaswami C, Theoharides TC. The effects of plant flavonoids on mammalian cells: implications for inflammation, heart disease, and cancer. Pharmacol Rev. 2000;52(4):673-751.

10. Matsumoto H, Nakamura Y, Iida H, Ito K, Ohguro H. Comparative assessment of distribution of blackcurrant anthocyanins in rabbit and rat ocular tissues. Exp Eye Res. 2006;83(2):348-356.

11. Kamiya K, Kobashi H, Fujiwara K, Ando W, Shimizu K. Effect of fermented bilberry extracts on visual outcomes in eyes with myopia: a prospective, randomized, placebo-controlled study. J Ocul Pharmacol Ther. 2013;29(3):356-359.

12. Vasudevan B, Esposito C, Peterson C, Coronado C, Ciuffreda KJ. Under-correction of human myopia - is it myopigenic?: a retrospective analysis of clinical refraction data. J Optom. 2014;7(3):147-152.

13. Walline JJ, Greiner KL, McVey ME, Jones-Jordan LA. Multifocal contact lens myopia control. Optom Vis Sci. 2013;90(11):1207-1214.

14. Lam CS, Tang WC, Tse DY, Tang YY, To CH. Defocus Incorporated Soft Contact (DISC) lens slows myopia progression in Hong Kong Chinese schoolchildren: a 2-year randomised clinical trial. $\mathrm{Br} \mathrm{J}$ Ophthalmol. 2014;98(1):40-45.

15. Pauné J, Morales H, Armengol J, Quevedo L, Faria-Ribeiro M, GonzálezMéijome JM. Myopia control with a novel peripheral gradient soft lens and orthokeratology: a 2-year clinical trial. Biomed Res Int. 2015; 2015:1-10

16. Kamiya K, Kobashi H, Fujiwara K, Ando W, Shimizu K. Effect of fermented bilberry extracts on visual outcomes in eyes with myopia: a prospective, randomized, placebo-controlled study. JOcul Pharmacol Ther. 2013;29(3):356-359.

17. Zhou WW, Deng HW, Liao CP, Xie HT. Short-term study of orally administered Difrarel to control myopia in children. Int J Ophthalmol. 2016;16(3):575-578.

18. Deng HW, Tian Y, Zhou XJ, Zhang XM, Meng J. Effect of bilberry extract on development of form-deprivation myopia in the guinea pig. J Ocul Pharmacol Ther. 2016;32(4):196-202.
19. Chua WH, Balakrishnan V, Chan YH, et al. Atropine for the treatment of childhood myopia. Ophthalmology. 2006;113(12):2285-2291.

20. Chia A, Chua WH, Cheung YB, et al. Atropine for the treatment of childhood myopia: safety and efficacy of $0.5 \%, 0.1 \%$, and $0.01 \%$ doses (Atropine for the Treatment of Myopia 2). Ophthalmology. 2012;119(2): 347-354.

21. Chia A, Chua WH, Wen L, Fong A, Goon YY, Tan D. Atropine for the treatment of childhood myopia: changes after stopping atropine $0.01 \%$, 0.1\% and 0.5\%. Am J Ophthalmol. 2014;157(2):451-457.e1

22. Blacker A, Mitchell GL, Bullimore MA, et al. Myopia progression during three years of soft contact lens wear. Optom Vis Sci. 2009; 86(10):1150-1153.

23. Walline JJ, Jones LA, Mutti DO, Zadnik K. A randomized trial of the effects of rigid contact lenses on myopia progression. Arch Ophthalmol. 2004;122(12):1760-1766

24. Lam CS, Tang WC, Tse DY, Tang YY, To CH. Defocus Incorporated Soft Contact (DISC) lens slows myopia progression in Hong Kong Chinese schoolchildren: a 2-year randomised clinical trial. $\mathrm{Br} J$ Ophthalmol. 2014;98(1):40-45.

25. Anstice NS, Phillips JR. Effect of dual-focus soft contact lens wear on axial myopia progression in children. Ophthalmology. 2011;118(6): 1152-1161.

26. Chen C, Cheung SW, Cho P. Myopia control using toric orthokeratology (TO-SEE study). Invest Ophthalmol Vis Sci. 2013;54(10):6510-6517.

27. Swarbrick HA, Alharbi A, Watt K, Lum E, Kang P. Myopia control during orthokeratology lens wear in children using a novel study design. Ophthalmology. 2015;122(3):620-630.

28. Watt KG, Swarbrick HA. Trends in microbial keratitis associated with orthokeratology. Eye Contact Lens. 2007;33(6 Pt 2):373-377; discussion 382.

29. Shehadeh-Masha'our R, Segev F, Barequet IS, Ton Y, Garzozi HJ. Orthokeratology associated microbial keratitis. Eur J Ophthalmol. 2009;19(1):133-136.
Clinical Ophthalmology

\section{Publish your work in this journal}

Clinical Ophthalmology is an international, peer-reviewed journa covering all subspecialties within ophthalmology. Key topics include: Optometry; Visual science; Pharmacology and drug therapy in eye diseases; Basic Sciences; Primary and Secondary eye care; Patien Safety and Quality of Care Improvements. This journal is indexed on

\section{Dovepress}

PubMed Central and CAS, and is the official journal of The Society of Clinical Ophthalmology (SCO). The manuscript management system is completely online and includes a very quick and fair peer-review system, which is all easy to use. Visit http://www.dovepress.com/ testimonials.php to read real quotes from published authors. 